\title{
Destruction Feature Extraction of Prefabricated Residential Building Components Based on BIM
}

\author{
Peili Zhao, ${ }^{1}$ Xiaohong Liu, ${ }^{2}$ and Zhisheng Liang $\mathbb{D}^{2}$ \\ ${ }^{1}$ Department of Management Engineering, Guangxi Polytechnic of Construction, Nanning 530007, China \\ ${ }^{2}$ School of Information and Management, Guangxi Medical University, Nanning 530021, China \\ Correspondence should be addressed to Zhisheng Liang; liangzhsh@stu.gxmu.edu.cn
}

Received 4 November 2021; Revised 29 November 2021; Accepted 7 December 2021; Published 7 January 2022

Academic Editor: Le Sun

Copyright (c) 2022 Peili Zhao et al. This is an open access article distributed under the Creative Commons Attribution License, which permits unrestricted use, distribution, and reproduction in any medium, provided the original work is properly cited.

In order to improve the damage feature extraction effect of prefabricated residential building components and improve the structural stability of prefabricated residential components, this paper applies BIM technology to the structural feature analysis of prefabricated residential components. Moreover, this paper adopts the simple superposition method and combines the first strength theory of material mechanics to derive the formula for calculating the cracking torque of prefabricated residential building components under compound torsion. In addition, based on the variable-angle space truss model, this paper uses a simple superposition method to derive the calculation formula for the ultimate torque of composite torsion of fabricated residential building components and applies it to the BIM fabricated residential model. Finally, this paper constructs an intelligent BIM prefabricated residential building construction damage characteristic monitoring system. Through experimental research, it can be seen that the intelligent BIM prefabricated residential building construction damage feature monitoring system proposed in this paper can monitor the damage characteristics of prefabricated residential building construction and can predict the evolution of subsequent building features.

\section{Introduction}

Compared with low-rise buildings, high-rise buildings change from mainly resisting vertical loads to simultaneously bearing vertical and horizontal loads. High-rise buildings have more design requirements in terms of strength, stiffness, and ductility. This is because under the action of horizontal load, if the high-rise building structure has insufficient resistance to lateral deformation or low lateral stiffness, it will cause excessive lateral deformation. Under the combined action of vertical loads, additional internal forces will be generated, which will cause cracks or deformations in infill walls and building decoration, and structural damage will occur in serious cases [1]. Therefore, high-rise buildings must not only have sufficient strength during the design, but also have reasonable stiffness to ensure that the lateral deformation generated under the horizontal load meets the requirements of the code. At the same time, high-rise buildings must meet the requirements of the seismic code for "small earthquakes are not bad, moderate earthquakes can be repaired, and large earthquakes cannot fall." The conventional structure is a frameshear wall structure in terms of load-bearing system. The new structure is a box-type multitube structure, which is also a frame-shear wall structure in terms of load-bearing system. Frame-shear wall structure refers to adding an appropriate amount of shear walls to the frame structure, and they work together through the floor slab to meet the lateral requirements of the building [2]. In the case of little impact on the use function of the building, adding a proper amount of shear walls to the frame can significantly improve the lateral stiffness and bearing capacity of the structure. Therefore, the structural system has the advantages of both the frame and the shear wall structure and has strong applicability [3].

In this paper, BIM technology is applied to the damage feature extraction of prefabricated residential building construction. This method can effectively improve the reliability and construction effect of residential buildings, can 
prevent and eliminate residential risk factors in time, and can improve the safety of residential buildings.

\section{Related Work}

The literature [4] used a three-dimensional laser scanner to create a virtual 3D model of the Mevlana Museum of Konya History in Turkey. Literature [5] proposed a reconstruction method of historical building information model based on 3D laser scanning technology and digital pictures. In order to maintain the integrity of historical buildings, literature [6] proposed a method combining ground laser scanners and red-hot exterior images to obtain the detection of the protection status of historical buildings. Aiming at the insufficiency of digital technology in prefabricated residential buildings and the "secondary damage" caused by contact measurement to buildings, the literature [7] proposed a research idea of integrated internal and external three-dimensional modeling combining three-dimensional laser scanning technology and modern measurement methods, which provides high-precision data benchmarks for the future development, protection, maintenance, restoration, and reconstruction of cultural heritage of prefabricated residential buildings. The literature [8] applied three-dimensional laser scanning technology to complete threedimensional data collection of ancient buildings. Literature [9] uses the massive point cloud data obtained by 3D laser scanning as an example to study the detailed process of point cloud data acquisition and processing in the $3 \mathrm{D}$ reconstruction of prefabricated residential buildings.

Oblique photography modeling is to use aerial camera to shoot images of buildings from different angles and then use data processing software for three-dimensional modeling and finally output the model [10]. Oblique photography modeling is a new type of surveying and mapping method with a wide range of applications, and the final result is also very real. Literature [11] uses oblique photography and ITS technology to perform 3D modeling of the city, showing the ability of oblique photography technology to be able to model large-scale three-dimensional modeling. Literature [12] uses oblique photography technology to perform $3 \mathrm{D}$ modeling of the ancient city of Rome, and the output results truly reflect the magnificence of the ancient city of Rome on the computer. Oblique photography technology started late in our country, but there are many research results in this area. Literature [13] uses oblique photography technology to establish a three-dimensional model and evaluates the progress. Literature [14] uses oblique photography technology to perform three-dimensional reconstruction of prefabricated residential buildings. Although oblique photography technology can carry out large-scale 3D reconstruction of buildings, its modeling cost is high and the amount of data is huge. However, prefabricated residential buildings have many components. Aerial photography cannot capture all of the complete prefabricated residential buildings and will be affected by the obstruction of objects around the building. The original appearance of the prefabricated residential buildings cannot be completely preserved. It also takes a lot of manpower to modify the built model, so the oblique photography technique cannot be applied to the technical method of batch modeling of Hakka prefabricated residential buildings.

Manual geometric modeling is to use SketchUp, 3DMax, unity3D, CAD, and other modeling software to perform 3D modeling of prefabricated residential buildings based on the drawings and data of prefabricated residential buildings. It has not formed a mature modeling system for 3D modeling of prefabricated residential buildings. And frameworks, among them, manual geometric modeling, 3D laser scanning modeling, and other modeling technology methods, are all three-dimensional modeling for a single prefabricated residential building, and the digital data of the prefabricated residential building can be used for virtual simulation and digital media display. In [15], the oblique photography technology has high modeling cost and large amount of data. Therefore, there is no technical means for prefabricated residential buildings that can be used universally and can be used for batch three-dimensional modeling. In order to solve the problem of rapid 3D modeling of mass prefabricated residential buildings, 3D modeling technology based on CGA grammar rules has gradually become the current research focus. Literature [16] uses the CityEngine platform to design the CGA rules for the three-dimensional modeling of Fujian Tulou and establishes a three-dimensional model of prefabricated residential buildings. Literature [17] analyzes the characteristics of prefabricated residential buildings and conducts three-dimensional modeling of its roof and its CGA Grammar optimization research. Literature [18] uses CityEngine to study the 3D modeling method of Lanzhou furnished residential buildings. Literature [19] uses CityEngine to model 3D prefabricated residential buildings, which provides a scientific and reasonable basis for the protection of the core old city landscape pattern. Literature [20] uses CityEngine's CGA rule modeling technology to achieve the establishment of a three-dimensional model of prefabricated residential buildings.

\section{Research on the Damage Characteristics of Residential Building Construction}

In this paper, the force mechanism, failure characteristics, stiffness, energy dissipation, ductility and torsion bearing capacity calculation formulas of reinforced concrete members under pure torsion, compression torsion, bending torsion, and shear torsion are studied in depth.

3.1. Space Truss Model. After the component cracks, the concrete cracks along a 45-degree angle with the longitudinal axis and forms a spiral diagonal strut. Moreover, it works in conjunction with longitudinal ribs and stirrups to form a space truss that relies on the shear flow on the pipe wall to resist torque. The schematic diagram of the model is shown in Figure 1. The basic assumptions of the space truss model are shown in Table 1.

The force mechanism of this model is clear, and the formula is simple and easy to calculate. However, at the same time, it also has the following problems. (1) The model 


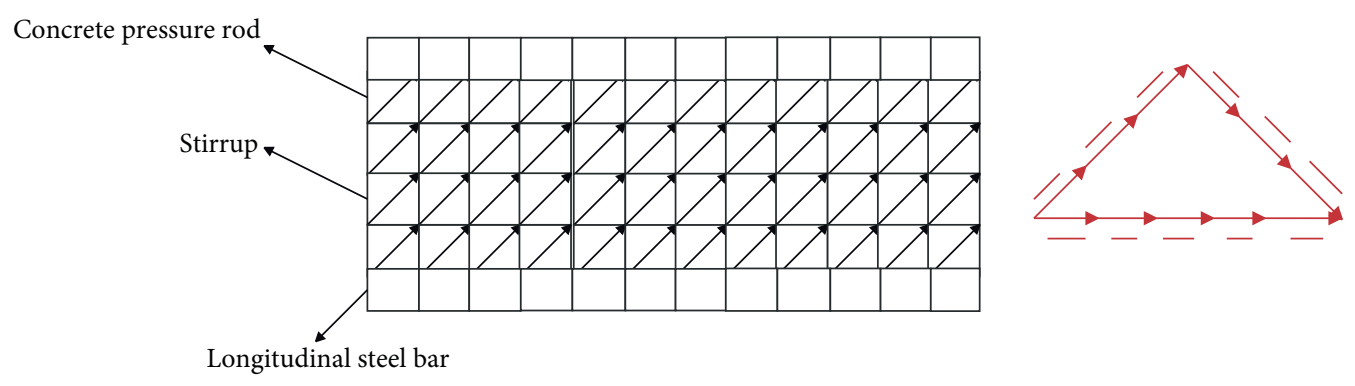

FIGURE 1: Space truss model.

TABLE 1: Basic assumptions of the space truss model.

Basic assumption

type

Basic assumption content

Basic assumption 1 The longitudinal bars and stirrups and the concrete diagonal struts are hinged at the nodes to form a space truss structure

Basic assumption 2

It is only considered that the concrete diagonal compression rod bears the axial pressure, and the shear capacity is ignored

Basic assumption 3 Longitudinal bars and stirrups only bear tensile force and do not consider the bolting effect of steel bars Basic assumption $4 \quad$ It ignores the torsion resistance of the concrete in the core area

ignores the torsion resistance of the concrete. After the component is cracked, the steel bar and the concrete at the edge of the crack still interact, which can limit the development of the crack, so the calculation of the torsion bearing capacity of the component is conservative. (2) The model does not consider that the strength ratio of stirrups and longitudinal reinforcements will affect the torsion bearing capacity of components. Moreover, it assumes that the amounts of longitudinal reinforcement and stirrup are equal and ignores the influence of redundant longitudinal reinforcement and stirrup on the torsional bearing capacity of the member, which directly causes the increase in the amount of reinforcement and increases the production cost. (3) For reinforced concrete members with a higher reinforcement ratio, because the members cannot all reach yield, a higher estimate of the torsion bearing capacity of the steel bars makes the calculation structure unsafe.

\subsection{Theoretical Model of Oblique Bending Failure. An obli-} que bending failure model is proposed on the basis of the combined bending, shear, and torsion test. The schematic diagram is shown in Figure 2. The model considers that the failure of the component occurs at the space section created by the spiral crack. With the change of cross-sectional shape, torsion ratio, and reinforcement ratio, the position of the compression zone of the failure surface will also change, which can be on the bottom, top, or side of the cross section. The model believes that the torsion member forms a spacedeflection failure section through a compression surface and three tension surfaces. The oblique bending failure model uses the internal and external moments of the neutral axis of the failure surface to use the balance of the internal and external moments to derive the calculation formula of the ultimate torsion bearing capacity.
After idealizing the failure section, another calculation model is proposed. It is considered that the failure section is at a 45-degree angle to the beam axis and a 90-degree angle to the wide face of the beam. The failure surface does not intersect the short-leg stirrups, and the impact of the shortleg on the torsional bearing capacity is not considered. The conclusions drawn according to these assumptions are consistent with the fact that the short-leg stirrup stress is relatively small in the experiment. In addition, this model also considers the pinning effect of concrete and longitudinal reinforcement in the compression zone and the shearing effect of concrete.

3.3. Variable-Angle Space Truss Model. In the space truss model, the inclination angle $\theta$ of the concrete oblique strut is a constant, while the variable-angle space truss model considers the inclination $\theta$ of the concrete oblique strut to be a variable, and the size of $\theta$ is determined by the relative magnitude of the yield stress of the stirrup and the longitudinal reinforcement. In the design process, we determine the size of $\theta$ according to the most economic ratio of the amount of stirrup and longitudinal reinforcement. The schematic diagram of the variable-angle space truss model is shown in Figure 3. The variable-angle space truss model also has four basic assumptions, as shown in Table 2.

3.4. Baroclinic Field Calculation Model. Based on the space truss model, the geometric deformation conditions and static equilibrium conditions of the members are considered at the same time, and this theory is applied to prestressed concrete structures. This model assumes that, after the component cracks, the concrete no longer resists the pulling force, and the torsion is completely resisted by the diagonal struts. The inclination angle of the reinforced concrete 

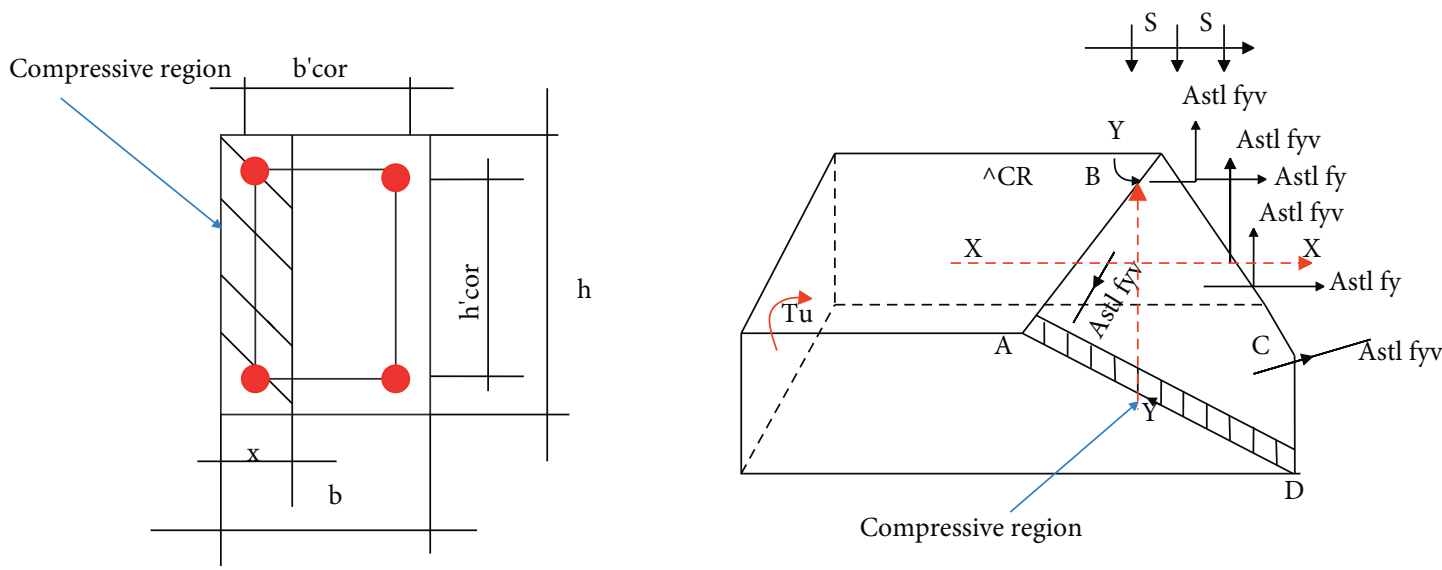

FIgURE 2: Calculation model of oblique bending theory.
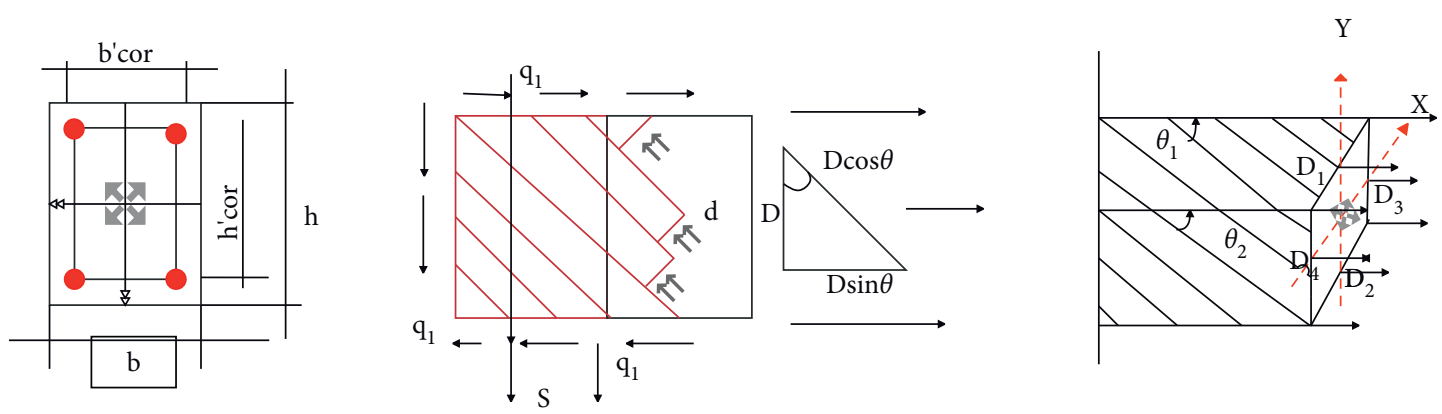

Figure 3: Variable-angle space truss model.

TABLE 2: Basic assumptions of the variable-angle space truss model.

Basic assumption

type

Basic assumption content

Basic assumption 1

The oblique concrete rod formed by the spiral crack only bears pressure, and the inclination angle is $\theta$

Basic assumption 2

The stirrups are regarded as the web members of the space truss, and the longitudinal ribs are regarded as the chords of the space truss, which only bear pressure

Basic assumption 3 It ignores the torsion effect of the concrete in the core area

Basic assumption 4

Under the action of torque, a constant shear flow is formed along the side wall of the box section

oblique beam can be determined by the coordinated conditions of the torsion of the reinforced concrete member. At the same time, it also took the concrete protective layer withdrawal work as the starting point to reduce the area of the concrete core area, adjust the position of the shear flow, and adjust the space truss model's defect that the torsion bearing capacity is too high.

3.5. Coordinated Pressure Field Calculation Model. The "softened space truss model" believes that the development direction of cracks is perpendicular to the direction of the main tensile stress of the concrete, and there is no shear stress in the section where the crack occurs. The direction of the main compressive stress of the concrete directly determines the direction of the concrete diagonal compression bar. The model ignores the influence of shear stress at the crack section on the torsional bearing capacity of the member and only considers the contribution of the steel frame to the torsional bearing capacity of the member.

Because the strain of the steel bar before cracking of the reinforced concrete member is small, the influence of the steel bar can be ignored when calculating the cracking torque of the reinforced concrete member under pure torsion.

Under the action of torque, torsional shear stress $\tau_{i}$ will be generated in the section of plain concrete member, and the calculation formula of $\tau_{i}$ is shown as follows:

$$
\tau_{i}=\frac{T}{W_{t}} .
$$

In the formula, $\mathrm{Wt}$ is the torsional plastic resistance moment of the section.

The torque generated by the component before it cracks is very small. Approximately analyze the stress distribution of the plain concrete member's section according to the elastic theory. 
When torque acts on a rectangular section, the maximum shear stress will be generated at the midpoint of the long side of the rectangular section, and a principal tensile stress equal to the torsional shear stress will be generated in the direction at $45^{\circ}$ to the longitudinal axis of the section. When the main tensile stress reaches the concrete tensile strength, the surface concrete cracks, and the development direction of the cracks forms an angle of $45^{\circ}$ with the longitudinal axis. Using the elastic theory, the formula for the cracking torque of concrete under pure torsion is obtained:

$$
T=\alpha f_{t} b h^{2} .
$$

In the formula, $\alpha$ is related to the ratio of long side $b$ and short side $h$ of the section, which can be obtained by looking up the table, $f_{t}$ is the tensile strength of concrete, and $b$ and $h$ are the long side and the short side of the component section.

When calculating the cracking torque of concrete members according to plastic theory, it is assumed that concrete is an ideal plastic material. As the torque increases, the cross section of the component begins to enter the plastic state from part to the full plastic state. At this time, the concrete stress on the cross section of the component all reaches the tensile strength of the concrete, and the cross section of the component is cracked. At this time, the plastic torsion resistance moment $W_{t}$ of the cross section of the member can be obtained according to the sand pile analogy method. The sand pile analogy method is shown in Figure 4.

$$
\begin{aligned}
V & =\frac{1}{12} \tau_{t} b^{2}(3 h-b), \\
\tau_{i} & =T=2 V \\
& =\frac{1}{6} b^{2}(3 h-b) .
\end{aligned}
$$

The formula for calculating the cracking torque of the component is

$$
\begin{aligned}
T_{\sigma} & =f_{t} W_{t} \\
& =f_{t} \frac{1}{6} b^{2}(3 h-b) .
\end{aligned}
$$

Concrete is an elastoplastic material between plastic and elastic materials. For reinforced concrete members under pure torsion, at the initial stage of torque, the stress distribution of the cross section can be approximated by elastic theory analysis. However, the stress distribution of the cross section gradually enters the elastoplastic stage as the torque increases. If calculated completely according to the plastic theory, the cracking torque of the component will be overestimated. If calculated completely according to the elastic theory, the cracking torque of the component will be underestimated, especially as the strength of the concrete increases, the brittleness of the concrete increases. In order to facilitate the calculation, we use the ideal plastic theory to approximate the cracking torque of reinforced concrete members, but the tensile strength of concrete should be
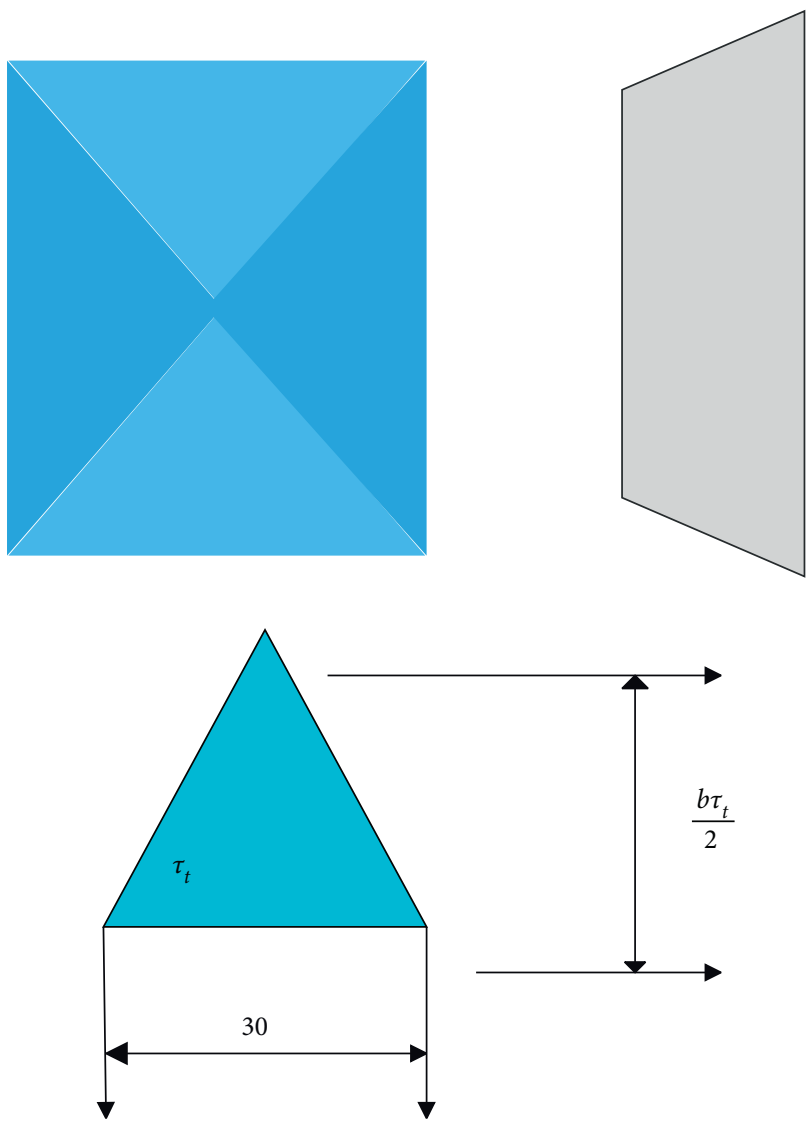

Figure 4: Schematic diagram of sand pile analogy method.

appropriately reduced. When calculating the cracking torque of reinforced concrete members under pure torsion, China's "Code for Design of Concrete Structures" (GB50010-2010) stipulates that a reduction factor should be multiplied on the basis of plasticity theory. The calculation formula is as follows:

$$
T_{\sigma}=\gamma_{t} f_{t} W_{t} .
$$

In the formula, $\gamma_{t}$ is the reduction factor, which is 0.8 for high-strength concrete and 0.7 for low-strength concrete.

We select a stress element at the middle edge of the column for research and obtain the principal tensile stress of the stress element according to the Moiré strength theory. When the principal tensile stress reaches the tensile strength of the concrete, it is considered that the concrete is cracked, namely:

$$
\sigma\{\sigma(N, M), \tau(T, V)\}=f_{t} .
$$

(1) The normal stress on the stress element is

$$
\sigma(N, M)=\sigma_{N}+\sigma_{M}
$$

For the convenience of calculation, we assume that the deformations of reinforced concrete and section steel are coordinated. At the same time, considering the role of longitudinal reinforcement, the axial pressure of the reinforced concrete part can be expressed as 


$$
\begin{aligned}
N_{1} & =\frac{f_{c} A+f_{y} A_{s}}{f_{c} A+f_{y} A_{s}+f_{a} A_{a}} \\
& =\alpha_{1} N .
\end{aligned}
$$

The compressive stress generated by the shaft pressure is

$$
\sigma_{N}=\frac{N_{1}}{A} \text {. }
$$

For H-shaped steel, before the concrete cracks, the strain of the steel flange is small. For simple calculation, all the bending moment is borne by the reinforced concrete and then the compressive stress generated by the bending moment is as follows:

$$
\sigma_{M}=\frac{M}{W}
$$

In the formula, $\mathrm{A}$ is the cross-sectional area of the member, $\mathrm{A}=\mathrm{bh}$; $W$ is the section flexural modulus of the component, and rectangular section is $W=b h^{2} / 6$.

(2) The shear stress on the stress element is

$$
\tau(T, V)=\tau_{T}+\tau_{V}
$$

According to the shear stiffness, the shear force borne by the concrete part and the section steel part is distributed, and the shear force borne by the concrete part is

$$
\begin{aligned}
V_{1} & =\frac{\tau_{c} b h}{\tau_{c} b h+\tau_{a} t_{w} b_{w}} V \\
& =\alpha_{2} V .
\end{aligned}
$$

The shear stress generated by the shear force is

$$
\tau_{V}=\frac{V_{1} S}{b I_{0}} \text {. }
$$

In the formula, $\tau_{c}$ and $\tau_{a}$ are the shear strength of concrete and section steel; $t_{w}$ and $b_{w}$ are the thickness and width of section steel web; $S$ is the static moment of cross section; and $I_{0}$ is the moment of inertia of the cross section on the neutral axis.

It is the same as the steel-concrete component under pure torsion; regardless of the influence of the steel on the cracking torque, the torque is all borne by the concrete part. Then, the shear stress generated by the torque is

$$
\tau_{T}=\frac{T_{c r}}{W_{t}}
$$

According to the formula of Mohr's strength theory, under the action of compressive stress $\sigma$ and shear stress $t$, the main tensile stress is

$$
\sigma_{t}=\frac{\sigma_{M}-\sigma_{N}}{2}+\sqrt{\left(\frac{\sigma_{M}-\sigma_{N}}{2}\right)^{2}+\tau^{2}} .
$$

If $\sigma_{t}=f_{t}$, then

$$
f_{t}=\frac{\sigma_{M}-\sigma_{N}}{2}+\sqrt{\left(\frac{\sigma_{M}-\sigma_{N}}{2}\right)^{2}+\tau^{2}} .
$$

Through sorting, we can get

$$
T_{c r}=f_{t} W_{t}\left(\sqrt{1+\frac{\alpha_{1} N}{f_{t} A}-\frac{M}{f_{t} W}}-\frac{\alpha V}{f_{t} b I_{0}}\right) .
$$

$\gamma$ is the influence coefficient considering the axial pressure, bending moment, and shear force on the cracking torque of steel reinforced concrete members under combined torsion; then,

$$
\begin{aligned}
\gamma & =\sqrt{1+\frac{\alpha_{1} N}{f_{t} A}-\frac{M}{f_{t} W}}-\frac{\alpha V}{f_{t} b I_{0}} \\
T_{c r} & =\gamma f_{t} W_{t} .
\end{aligned}
$$

With the decrease of the torsion-bending ratio, the failure mode of steel reinforced concrete members gradually changes from torsion failure to bending failure. When the first crack appears at the neutral axis of the shear superimposed surface, the influence of the bending moment on the cracking torque of the component can be ignored. When the first crack appears on the curved tensile surface, it is necessary to consider the influence of bending moment, shear force, and axial pressure on the cracking torque of the component at the same time.

According to observations, the first crack in this test generally appears in the middle of the shear superimposed surface. At this time, the bending deformation of the steel reinforced concrete member is very small, and the crack is generally located at the neutral axis, and the bending moment can be approximately regarded as zero. Taking into account that concrete is an elastoplastic material and its softening properties at failure, it is multiplied by the torque reduction coefficient $\mathrm{K}$ on the right side of (19) to obtain the formula:

$$
\begin{aligned}
T_{c r} & =K \gamma f_{t} W_{t} \\
& =K f_{t} W_{t}\left(\sqrt{1+\frac{\alpha_{1} N}{f_{t} A}-\frac{M}{f_{t} W}}-\frac{\alpha_{2} V}{f_{t} b I_{0}}\right) .
\end{aligned}
$$

Under pure torsion, the external reinforced concrete bears most of the torque. Because the external concrete restricts the deformation of the internal steel, the calculation of the torsional bearing capacity of the internal steel is more complicated. In the actual engineering design, the relationship between the effective wall thickness of the torsion member and the thickness of the steel reinforced concrete protective layer should be considered first. When the thickness of the steel reinforced concrete protective layer is large, the effect of the internal steel can be ignored, and only the torsion bearing capacity of the reinforced concrete members can be calculated. The empirical formula of the ultimate torque obtained from the test of reinforced concrete members in China is

$$
T_{R C}=0.35 f_{t} W_{t}+1.2 \sqrt{\xi} \frac{A_{s v} f_{y v} A_{c o r}}{s} .
$$

In the formula, $f_{t}$ is the concrete tensile strength; $W_{t}$ is the torsional plastic resistance of the section; $\xi$ is the reinforcement strength ratio considering the influence of 
section steel, $0.6 \leq \xi \leq 1.7 ; f_{y v}{ }^{\prime} A_{s v}$ is the design value of the tensile strength of the torsion stirrup and the cross-sectional area of the torsion stirrup; $A_{\text {cor }}$ is the area of the core area of concrete components; and $s$ is the stirrup spacing.

When the thickness of the protective layer of steel section concrete is small, the ultimate torque of section steel-concrete members can be obtained by superimposing the respective torques borne by section steel and concrete, and the concrete part can be obtained from the above formula. The full plastic torque of $\mathrm{H}$-shaped steel can still be divided into two parts: warping torsion and free torsion. In this case, the simple superposition method can be used for calculation; the formula is as follows:

$$
T_{S R C}=T_{B C}+T_{a}=T_{R C}+T_{u}+T_{w}
$$

In the formula, $T_{R C}$ is the torque borne by a reinforced concrete part; $T_{u}$ is the free torsion torque of section steel; and $T_{\mathrm{w}}$ is the warping torque of the section steel.

Substituting the full plastic free torsion torque $T_{u}$ and the full plastic warping torsion torque $T_{\mathrm{w}}$ into the formula, we get

$$
T_{S R C}=0.35 f_{t} W_{t}+1.2 \sqrt{\xi} \frac{A_{s v} f_{y v} A_{c o r}}{s}+\frac{f_{y}}{\sqrt{3}}\left[b t^{2}\left(1-\frac{t}{3 b}\right)+h_{0} \frac{t_{w}^{2}}{2}+\frac{t_{w}^{2}}{6}\right]+\frac{2 M_{f p} h_{0}}{L} .
$$

When the member is in the limit state, the warping torsion torque is generally $22-033$ of the free torsion torque, and the free torsion torque increase coefficient $\alpha$ of the section steel is introduced, and then (23) is obtained on the basis of (22):

$$
T_{S R C}=0.35 f_{t} W_{t}+1.2 \sqrt{\xi} \frac{A_{s v} f_{y v} A_{c o r}}{s}+\alpha \frac{f_{y}}{\sqrt{3}}\left[b t^{2}\left(1-\frac{t}{3 b}\right)+h_{0} \frac{t_{w}^{2}}{2}+\frac{t_{w}^{2}}{6}\right]
$$

Based on the spatial variable-angle analysis frame model, the strength-related equations of reinforced concrete members under bidirectional compression, bending, shear and torsion are obtained:

$$
\frac{T_{1}^{2}}{T_{0}^{2}}+\frac{V_{x}^{2}}{v_{0 X}^{2}}+\frac{V_{Y}^{2}}{v_{0 Y}^{2}}+\frac{M_{x}}{M_{0 x}}+\frac{M_{y}}{M_{0 y}}-\frac{N_{1}}{N_{0}}=1 .
$$

This experiment is the analysis of the unidirectional compression, bending, shear, and torsion force of steel reinforced concrete members. The equation is simplified as

$$
\frac{T_{1}^{2}}{T_{0}^{2}}+\frac{V_{1}^{2}}{V_{0}^{2}}+\frac{M_{1}}{M_{0}}-\frac{N_{1}}{N_{0}}=1
$$

In the formula,

$$
\begin{aligned}
T_{0} & =2 A_{\text {cor }} \sqrt{\frac{f_{y} A_{s t l}}{u_{\text {cor }}} \cdot \frac{A_{s v} f_{y v}}{s},} \\
V_{0} & =\frac{A}{t_{2}+t_{4}} \sqrt{2 \cdot \frac{f_{y} A_{s t l}}{b_{\text {cor }}} \cdot \frac{A_{s v} f_{y v}}{s}}, \\
N_{0} & =\frac{A_{s t l} f_{y}}{\beta_{N}}, \\
M_{0} & =\frac{3 A_{s t l} f_{y} b l}{8} .
\end{aligned}
$$

According to Figure 3, we take

$$
\begin{aligned}
& t_{1}=t_{3}=\frac{b}{5}, \\
& t_{2}=t_{4}=\frac{h}{5} .
\end{aligned}
$$

Then,

$$
\begin{aligned}
\beta_{N} & =\frac{A}{A} \\
& =1-\frac{\left(b-t_{1}-t_{3}\right)\left(h-t_{2}\right.}{b h} \\
& =0.64 \\
V_{0} & =\sqrt{\frac{125 b f_{y} A_{s t l} f_{y v} A_{s v}}{8}}, \\
N_{0} & =\frac{f_{y} A_{s t l}}{0.64}, \\
M_{0} & =0.3 b f_{y} A_{s t l} .
\end{aligned}
$$$$
=1-\frac{\left(b-t_{1}-t_{3}\right)\left(h-t_{2}-t_{4}\right)}{b h}
$$

$\mathrm{T} 1, \mathrm{~V} 1, \mathrm{M} 1$, and $\mathrm{N} 1$ are, respectively, the torque, shear force, bending moment, and axial pressure of the reinforced concrete part under the action of compression, bending, shear, and torsion, which are distributed according to the following formula. 


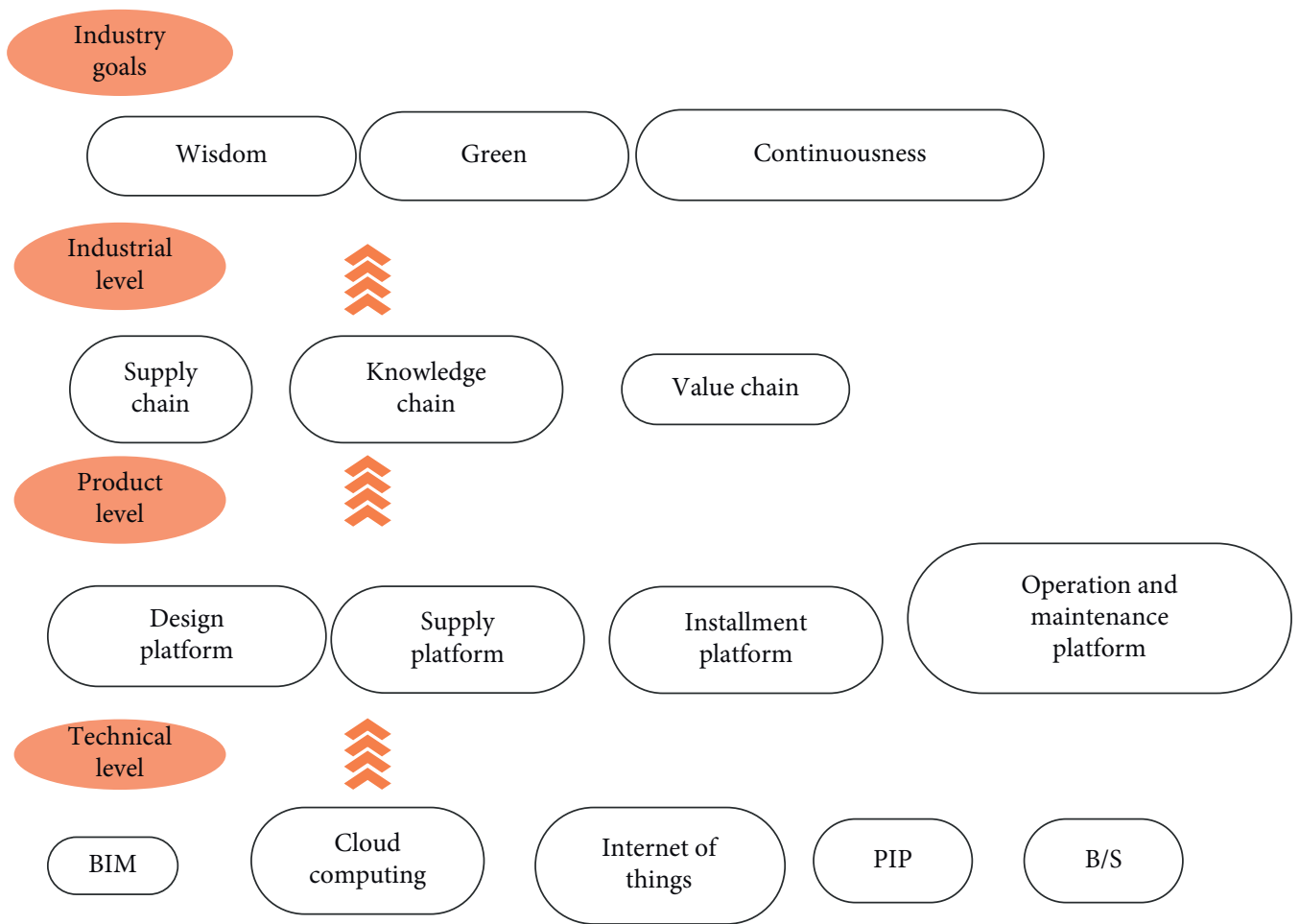

FIGURE 5: Roadmap of the R\&D technology of the integrated management platform.

3.5.1. Torque Distribution. According to (23), referring to formulas (20) and (21), the torsion bearing capacity of steelconcrete members under pure torsion is superimposed according to the torque borne by the reinforced concrete part and the torque borne by the steel part:

$$
\begin{aligned}
T_{1} & =\frac{T_{R C}}{T_{R C}+T_{a}} \\
& =\alpha_{1} T .
\end{aligned}
$$

In the formula, $\alpha_{1}$ is the percentage of torque borne by the reinforced concrete part.

\subsubsection{Shear Force Distribution.}

$$
\begin{aligned}
V_{1} & =\frac{\tau_{c} b h}{\tau_{c} b h+\tau_{a} t_{w} b_{w}} V \\
& =\alpha_{2} V .
\end{aligned}
$$

In the formula, $\tau_{c}$ and $\tau_{a}$ are the shear strength of concrete and section steel; $t_{\mathrm{w}}$ and $b_{\mathrm{w}}$ are the thickness and width of the profiled steel web; $\alpha 2$ is the percentage of shear force borne by the reinforced concrete part.

\subsubsection{Bending Moment Distribution.}

$$
\begin{aligned}
M_{1} & =\frac{f_{y} A_{s} h \prime}{f_{y} A_{s} h \prime+f_{a} A_{a f} h \prime \prime} \\
& =\alpha_{3} M .
\end{aligned}
$$

In the formula, $h$ is the distance from the point of action of tensile longitudinal bars to the point of action of compressed longitudinal bars; $h$ ' is the center distance of the steel flange; $A_{s}$ is the area of the longitudinal ribs on the bending and tensile side; $A_{A f}$ is the area of a single steel flange; and $\alpha_{s}$ is the percentage of bending moment borne by the reinforced concrete part.

\subsubsection{Axial Force Distribution.}

$$
\begin{aligned}
N_{1} & =\frac{f_{c} A_{c}+f_{y} A_{s t l}}{f_{s} A_{c}+f_{y} A_{s t l}+f_{a} A_{a}} \\
& =\alpha_{4} N .
\end{aligned}
$$

$\alpha$ is the percentage of axial pressure borne by the reinforced concrete part.

Substituting (29), (30), (31), and (32) into (25), the strength-related equations of $\mathrm{H}$-shaped steel-concrete members are obtained.

The ultimate bearing capacity $T$ of steel reinforced concrete members under composite torsion is

$$
\left(\frac{\alpha_{1} T}{T_{0}}\right)^{2}+\left(\frac{\alpha_{2} V}{V_{0}}\right)^{2}+\frac{\alpha_{3} M}{M_{0}}+\frac{\alpha_{4} N}{N_{0}}=1
$$

Substituting (19) for the ultimate torque of reinforced concrete members under pure torsion into (34), we get

$$
T_{u}=\frac{T_{0}}{\alpha_{1}} \sqrt{1-\left(\frac{\alpha_{2} V}{V_{0}}\right)^{2}-\frac{\alpha_{3} M}{M_{0}}+\frac{\alpha_{4} N}{N_{0}}} .
$$




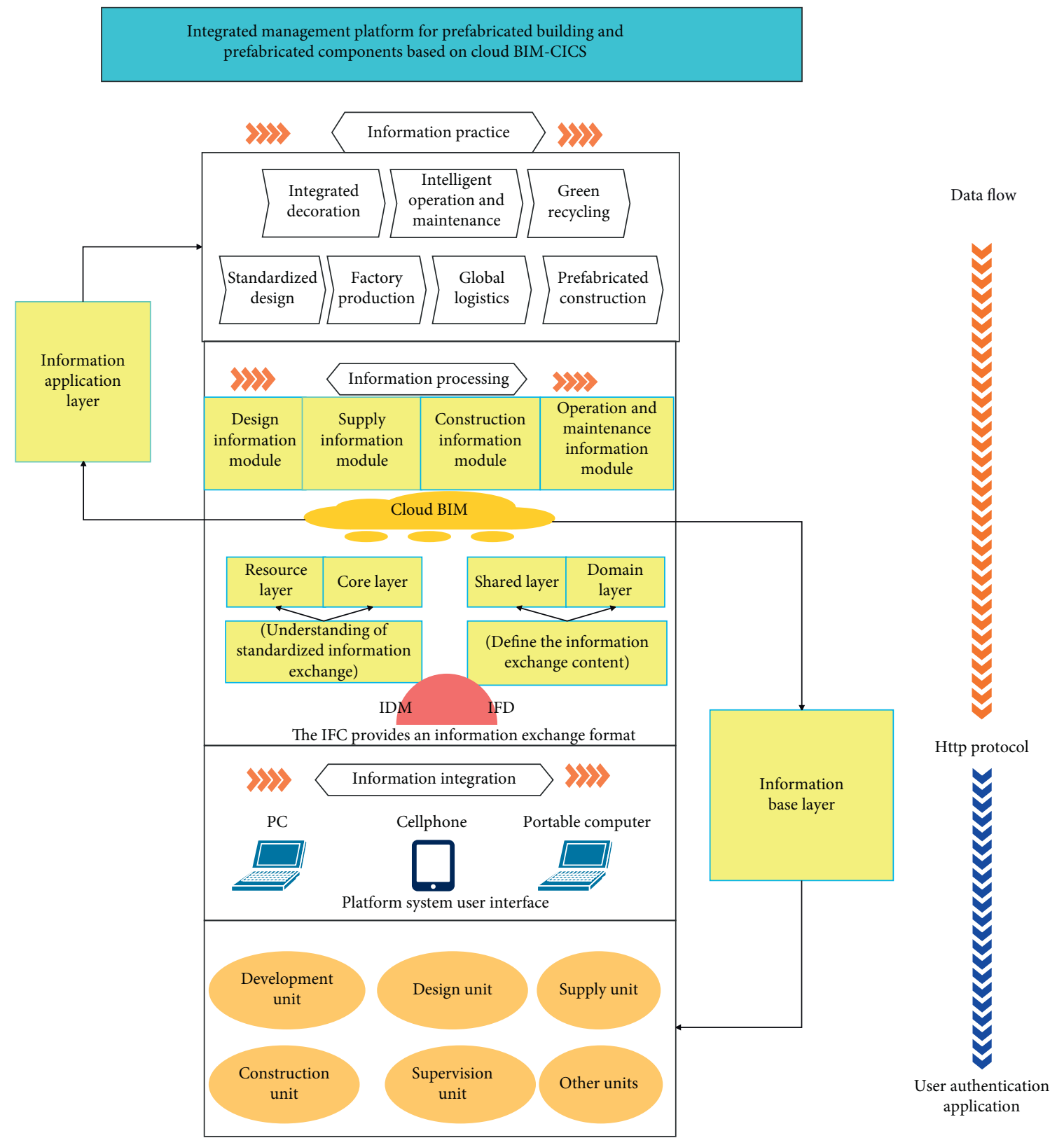

FIGURE 6: Architecture diagram of integrated management platform for prefabricated components.

\section{Construction Damage Feature Extraction of Prefabricated Residential Buildings Based on BIM}

The development of an integrated management platform for prefabricated building components based on cloud BIMCICS integrates technologies such as cloud BIM, Internet of Things, networks, and databases. Based on the design idea of the integrated management platform, this paper is oriented to the business points of prefabricated component management of prefabricated buildings and determines the R\&D technical route of the platform, as shown in Figure 5.

Based on the cloud BIM technology and the characteristics of China's prefabricated component management and the goals of the platform, this paper determines the prefabricated component integrated management platform architecture of the prefabricated building based on cloud BIM-CICS, as shown in Figure 6. The platform realizes the integrated management of industry chain information, allows production information to "flow," realizes effective sharing of information in various links such as component design, supply, installation, operation, and maintenance, and improves project management efficiency.

Combined with the demand for extraction of damage characteristics of prefabricated residential buildings, this paper constructs an intelligent BIM prefabricated residential building construction damage feature monitoring system as shown in Figure 7.

After the above intelligent system is constructed, the damage feature monitoring effect of the system in this paper 
Components marked red

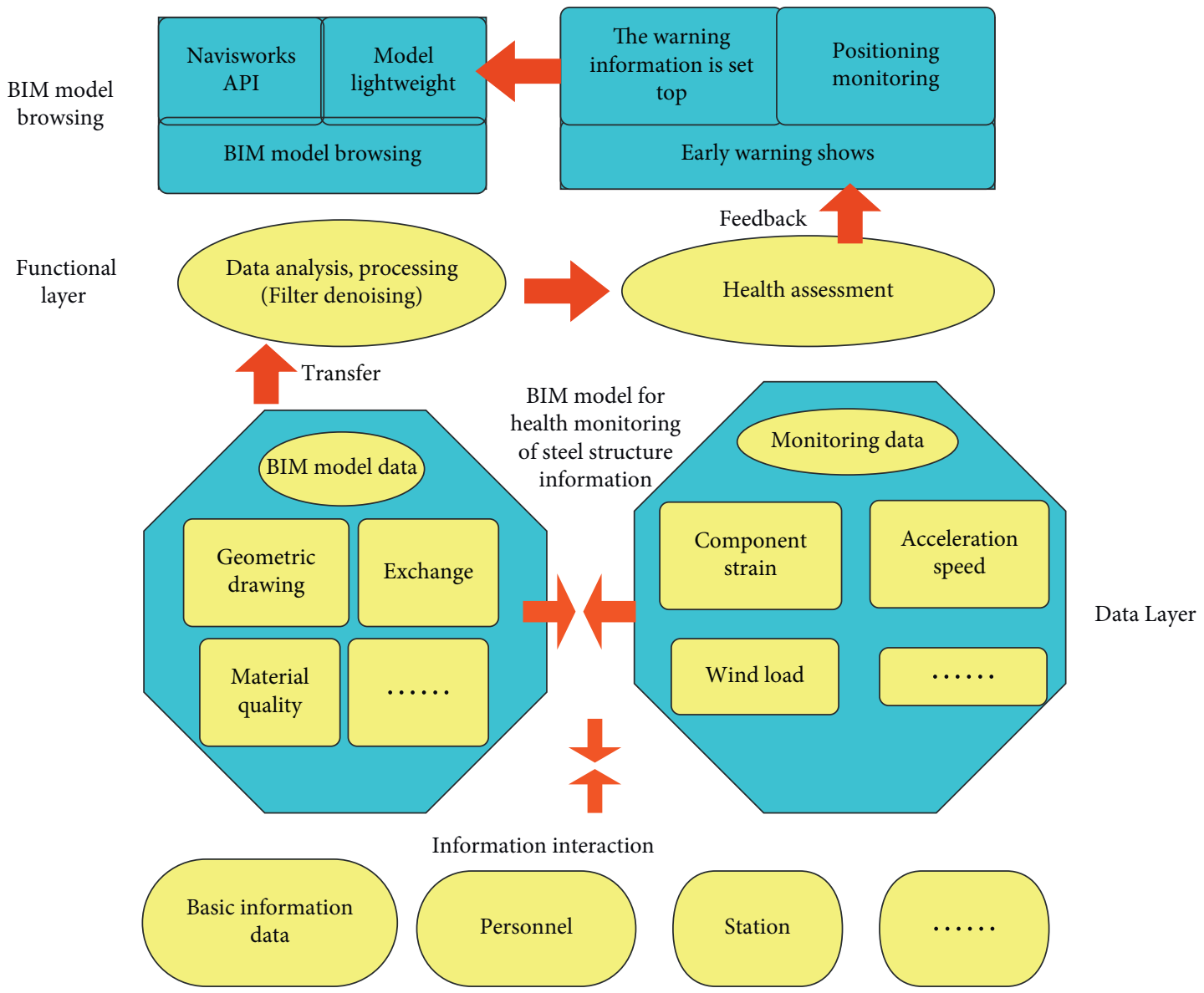

FIGURE 7: Intelligent BIM prefabricated residential building construction damage feature monitoring system.

TABLE 3: The monitoring effect of residential building damage feature of intelligent BIM prefabricated residential building construction damage feature monitoring system.

\begin{tabular}{|c|c|c|c|c|c|}
\hline No. & Feature monitoring & No. & Feature monitoring & No. & Feature monitoring \\
\hline 1 & 86.7 & 20 & 78.3 & 39 & 87.7 \\
\hline 2 & 75.3 & 21 & 86.4 & 40 & 75.7 \\
\hline 3 & 79.5 & 22 & 88.7 & 41 & 80.8 \\
\hline 4 & 78.4 & 23 & 76.4 & 42 & 84.5 \\
\hline 5 & 89.2 & 24 & 77.2 & 43 & 82.7 \\
\hline 6 & 93.9 & 25 & 81.7 & 44 & 75.0 \\
\hline 7 & 89.2 & 26 & 74.7 & 45 & 90.5 \\
\hline 8 & 87.9 & 27 & 80.6 & 46 & 76.9 \\
\hline 9 & 86.9 & 28 & 81.1 & 47 & 87.1 \\
\hline 10 & 91.3 & 29 & 74.1 & 48 & 82.8 \\
\hline 11 & 86.9 & 30 & 75.6 & 49 & 78.4 \\
\hline 12 & 78.1 & 31 & 90.5 & 50 & 78.8 \\
\hline 13 & 84.1 & 32 & 76.8 & 51 & 86.6 \\
\hline 14 & 90.0 & 33 & 83.8 & 52 & 81.9 \\
\hline 15 & 88.7 & 34 & 91.8 & 53 & 83.6 \\
\hline 16 & 75.6 & 35 & 81.0 & 54 & 85.7 \\
\hline 17 & 76.2 & 36 & 89.9 & 55 & 93.8 \\
\hline 18 & 91.6 & 37 & 92.6 & 56 & 79.7 \\
\hline 19 & 78.2 & 38 & 74.9 & & \\
\hline
\end{tabular}


TABLE 4: The prediction effect of residential building component features of intelligent BIM prefabricated residential building construction damage feature monitoring system.

\begin{tabular}{|c|c|c|c|c|c|}
\hline No. & Feature prediction & No. & Feature prediction & No. & Feature prediction \\
\hline 1 & 85.2 & 20 & 71.0 & 39 & 81.6 \\
\hline 2 & 71.5 & 21 & 78.9 & 40 & 73.3 \\
\hline 3 & 77.9 & 22 & 68.4 & 41 & 68.0 \\
\hline 4 & 68.7 & 23 & 78.4 & 42 & 83.8 \\
\hline 5 & 70.9 & 24 & 82.6 & 43 & 70.0 \\
\hline 6 & 80.0 & 25 & 83.7 & 44 & 81.4 \\
\hline 7 & 79.8 & 26 & 84.6 & 45 & 68.1 \\
\hline 8 & 78.4 & 27 & 79.7 & 46 & 67.3 \\
\hline 9 & 87.3 & 28 & 75.7 & 47 & 87.9 \\
\hline 10 & 74.3 & 29 & 75.7 & 48 & 83.9 \\
\hline 11 & 86.8 & 30 & 73.0 & 49 & 80.0 \\
\hline 12 & 78.4 & 31 & 70.5 & 50 & 69.1 \\
\hline 13 & 74.3 & 32 & 86.1 & 51 & 87.4 \\
\hline 14 & 81.2 & 33 & 79.2 & 52 & 83.7 \\
\hline 15 & 82.5 & 34 & 78.0 & 53 & 81.3 \\
\hline 16 & 79.5 & 35 & 83.1 & 54 & 87.9 \\
\hline 17 & 67.7 & 36 & 75.9 & 55 & 71.7 \\
\hline 18 & 79.7 & 37 & 70.6 & 56 & 75.6 \\
\hline 19 & 83.2 & 38 & 67.1 & & \\
\hline
\end{tabular}

and the component feature prediction effect of the system in this paper are evaluated by simulation tests, and the results are shown in Tables 3 and 4.

From the above research, it can be seen that the intelligent BIM prefabricated residential building construction damage feature monitoring system proposed in this paper can monitor the damage characteristics of the prefabricated residential building construction and can predict the evolution of subsequent building features.

\section{Conclusion}

With the rapid development of the residential building industry, the structure and calculation theory of residential building structures are constantly improving and perfecting. In particular, the strength of steel has been greatly improved, which has further promoted the development of structural members in the direction of thin walls. In high-rise residential buildings, the lateral force resistance system transmits the horizontal load (wind, earthquake, and so on) that the house bears to the foundation. The high-rise residential building as a whole is regarded as a cantilever beam under the action of vertical and horizontal forces. As the height of the residential building increases, the vertical force at the bottom of the structure increases linearly, and the bending moment and lateral displacement of the bottom floor increase in an exponential curve. Therefore, as the height increases, the horizontal load will gradually become the dominant factor in the structural design, and the selection and composition of the lateral force-resistant structural system have become the primary consideration and decision-making focus of the structural design of high-rise residential buildings. In most cases, it is unified with the vertical load transfer system. In this paper, BIM technology is applied to the failure feature extraction of prefabricated residential building construction. This method can effectively improve the reliability and construction effect of residential buildings, can prevent and eliminate residential risk factors in time, and can improve the safety of residential buildings.

\section{Data Availability}

The labeled datasets used to support the findings of this study are available from the corresponding author upon request.

\section{Conflicts of Interest}

The authors declare that there are no conflicts of interest.

\section{Acknowledgments}

This study was sponsored by the Research Foundation of Young and Middle-aged Teachers in Guangxi Universities + Research on the Flexural Properties of Prefabricated Reinforced Concrete Partial Composite Plates (2020KY35019); 2020 Guangxi Vocational Education Teaching Reform Research Project (GXGZJG2020B053) Curriculum Reform and Practice of "Construction Project Management" under PC factory + Smart Site mode.

\section{References}

[1] D. Chakraborty and H. Elzarka, "Advanced machine learning techniques for building performance simulation: a comparative analysis," Journal of Building Performance Simulation, vol. 12, no. 2, pp. 193-207, 2019.

[2] O. Guerra-Santin and S. Silvester, "Development of dutch occupancy and heating profiles for building simulation," Building Research \& Information, vol. 45, no. 4, pp. 396-413, 2017.

[3] T. Dodd, C. Yan, and I. Ivanov, "Simulation-based methods for model building and refinement in cryoelectron 
microscopy," Journal of Chemical Information and Modeling, vol. 60, no. 5, pp. 2470-2483, 2020.

[4] T. Abuimara, W. O’Brien, B. Gunay, and J. S. Carrizo, “Towards occupant-centric simulation-aided building design: a case study," Building Research \& Information, vol. 47, no. 8, pp. 866-882, 2019.

[5] P. Remmen, M. Lauster, M. Mans, M. Fuchs, T. Osterhage, and D. Müller, "TEASER: an open tool for urban energy modelling of building stocks," Journal of Building Performance Simulation, vol. 11, no. 1, pp. 84-98, 2018.

[6] N. Endo, E. Shimoda, K. Goshome, T. Yamane, T. Nozu, and T. Maeda, "Simulation of design and operation of hydrogen energy utilization system for a zero emission building," International Journal of Hydrogen Energy, vol. 44, no. 14, pp. 7118-7124, 2019.

[7] M. I. Beausoleil, "Learning the fundamentals of building performance simulation through an experiential teaching approach," Journal of Building Performance Simulation, vol. 12 , no. 3, pp. 308-325, 2019.

[8] C. Xiong, J. Huang, and X. Lu, "Framework for city-scale building seismic resilience simulation and repair scheduling with labor constraints driven by time-history analysis," Computer-Aided Civil and Infrastructure Engineering, vol. 35, no. 4, pp. 322-341, 2020.

[9] A. D. Black, "Wor(l)d-Building: simulation and metaphor at the mars desert research station," Journal of Linguistic Anthropology, vol. 28, no. 2, pp. 137-155, 2018.

[10] K. Hanson, L. Hernandez, and J. A. Banaski, "Building simulation exercise capacity in Latin America to manage public health emergencies," Health security, vol. 16, pp. S98-S-102, 2018.

[11] E. K. Wati and N. Widiansyah, "Design of learning media: modeling \& simulation of building thermal comfort optimization system in building physics course," Jurnal Pendidikan IPA Indonesia, vol. 9, no. 2, pp. 257-266, 2020.

[12] C. W. Lee and S.-J. Cho, "The development of converting program from sealed geological model to gmsh, COMSOL for building simulation grid," Journal of the Korean Earth Science Society, vol. 38, no. 1, pp. 80-90, 2017.

[13] C. Miller, D. Thomas, J. Kämpf, and A. Schlueter, "Urban and building multiscale co-simulation: case study implementations on two university campuses," Journal of Building Performance Simulation, vol. 11, no. 3, pp. 309-321, 2018.

[14] X. Xie and Z. Gou, "Building performance simulation as an early intervention or late verification in architectural design: same performance outcome but different design solutions," Journal of Green Building, vol. 12, no. 1, pp. 45-61, 2017.

[15] A. I. Adilkhodjayev, I. M. Mahamataliev, and S. S. Shaumarov, "Theoretical aspects of structural and simulation modeling of the macrostructure of composite building materials," Journal of Tashkent Institute of Railway Engineers, vol. 14, no. 2, pp. 3-14, 2019.

[16] S. Imam, D. A. Coley, and I. Walker, "The building performance gap: are modellers literate?" Building Service Engineering Research and Technology, vol. 38, no. 3, pp. 351-375, 2017.

[17] J.-S. Pei, B. Carboni, and W. Lacarbonara, "Mem-models as building blocks for simulation and identification of hysteretic systems," Nonlinear Dynamics, vol. 100, no. 2, pp. 973-998, 2020.

[18] A. Brunelli, F. de Silva, A. Piro et al., "Numerical simulation of the seismic response and soil-structure interaction for a monitored masonry school building damaged by the 2016 central Italy earthquake," Bulletin of Earthquake Engineering, vol. 19, no. 2, pp. 1181-1211, 2021.

[19] P. Andrio, A. Hospital, J. Conejero et al., "Bioexcel building blocks, a software library for interoperable biomolecular simulation workflows," Scientific Data, vol. 6, no. 1, pp. 169-178, 2019.

[20] G. Petrou, A. Mavrogianni, P. Symonds et al., "Can the choice of building performance simulation tool significantly alter the level of predicted indoor overheating risk in London flats?" Building Service Engineering Research and Technology, vol. 40, no. 1, pp. 30-46, 2019. 